Revista Iberoamericana, Vol. LXXVII, Núm. 235, Abril-Junio 2011, 489-499

\title{
NANCY MOREJÓN: ARÁ ORÚN EN LA TIERRA
}

POR

Alan West-DuRÁn

Northeastern University

Yoruba believe strongly in the power of the word, or rather in a mysterious force called ashe...thatqualityinaman's personality which makes his words-once uttered-come true.

Ulli Beier

Nancy Morejón se crió en Los Sitios, barrio humilde de La Habana, en el seno de la cultura popular cubana. Allí, entre rumberos, santeros, náñigos, coros de clave y músicos, ella describe "una amorosa energía africana" que emanaba de sus calles, nutriendo su poesía que se ha publicado durante cincuenta años de producción literaria. En varios poemas Morejón alude directamente al mundo de los orishas, estando "Elegía a Nieves Fresneda” y “Los ojos de Eleggua” entre los más conocidos. Más provechoso es explorar los trazos de la filosofía yoruba o konga en poemas que no tratan directamente del tema. Creo que es significativo porque Morejón siempre ha rechazado, poéticamente hablando, un manejo "folclorista" de la cultura afrocubana, especialmente en sus expresiones religiosas (Regla de Ocha o Santería, la Regla de Palo y la religión Abakuá). Se trata, entonces, de una filosofía o visión del cosmos sentida y vivida en la piel, en los humildes ritmos de la calle, no un elaborado sistema de aparatosos conceptos que supuestamente ayudan a "explicar" el texto.

En "Los muertos", poema dedicado al crítico francés Jacques Gilard en su libro $L a$ Quinta de los Molinos (2000), no hay ningún “tema santero” en el sentido más obvio. Veamos cómo la poeta elabora el poema:

Los muertos son la ausencia, el olvido, lo inerte.

Una campana suena

balanceando su soledad entre las rosas.

Los muertos vienen de noche

o vienen por la tarde 


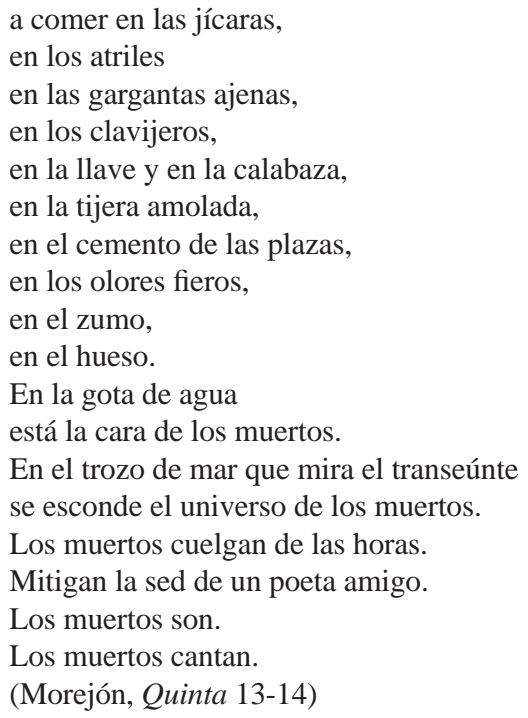

Aun los no santeros en Cuba entienden la importancia que tienen los muertos (los egún) en la Regla de Ocha, pues en el orden ritual de las ceremonias se le rinde homenaje a los egún antes que a los orishas. Como dice Patricia González,

The eggun-gun are the spirits of ancestors and some are the spiritual guides to a person at birth. After death, spirits remain around their relatives here on earth, for protection and guidance. Invoked in every religious ritual, they often participate in family decisions, giving their approval or disapproval in family affairs. (955)

Dada su importancia, a estos espíritus se les hacen ofrendas (velas, fruta, comida, etc.), como también cantos sagrados (con o sin tambores) y a veces mayores sacrificios. De igual forma, el santero tiene su bóveda espiritual con los vasos de agua para atraer a sus muertos protectores, sean familiares, espíritus yorubas, congos, indios, árabes, etc. Forman parte del cuadro espiritual de la persona e integran su comunidad espiritual que, claro, incluye a los vivos también. No hay ningún ritual o ceremonia de Ocha que no empiece con los muertos: el registro, la misa espiritual, la rogación de cabeza, los collares, los guerreros, el asiento. Todos comienzan invocando a los ancestros y a los muertos.

No olvidemos, tampoco, las prácticas de los paleros (Regla de Palo) y sus ngangas, el receptáculo que mantiene una activa y estrecha relación entre muertos y vivos. La misma elaboración del nganga nos recuerda ese vínculo que, además de palos, hierbas, tierra de bibijagüero, agua de mar, arena, insectos, en fin, de todo, incluye también huesos humanos y hasta calaveras (animales o humanas). La prenda es, como han observado

Revista Iberoamericana, Vol. LXXVII, Núm. 235, Abril-Junio 2011, $489-499$
ISSN 2154-4794 (Electrónico) 
muchos, una especie de microcosmos en una cazuela puesto a funcionar, a trabajar para los vivos. Ocha, Palo y Espiritismo están intimamente ligados en Cuba, cada una con su propia visión de la muerte y trato con los espíritus.

El poema empieza con lo doloroso: los muertos son "la ausencia, el olvido,/ lo inerte”. Morejón invoca tanto una condición física como mental o sicológica. La ausencia física se asocia con el olvido y por fin con la inmovilidad. Nada extraño aquí. Los próximos dos versos cambian de rumbo. Una campana suena entre rosas. ¿La campanita de Ochún? Luego empiezan los muertos a venir por la tarde o la noche y a “comer en las jícaras”, algo muy común en Ocha, donde las jícaras contienen agua para refrescar a los santos, omieros para limpieza u otras abluciones para fortalecer a los creyentes. Más poderoso es el verso “en las gargantas ajenas”, que recuerda una de las experiencias centrales de este mundo donde espíritus hablan por el cuerpo de la persona que los haya bajado. Esta posesión por un espíritu muestra la cercanía que hay entre el espiritismo y la santería. En muchas ocasiones son espíritus de ex-esclavos o de africanos o criollos que murieron siendo esclavos todavía, dándole a estos espirítus que habitan al cuerpo del vivo un peso histórico innegable.

Hay que presenciar la ceremonia de “cajón al muerto” para valorar las dimensiones del verso de Morejón. El cajón es una ceremonia donde se toca la rumba de cajón con el propósito de "bajar a los muertos” al mundo de los vivos. En un cajón que presencié en 2006, el médium -un joven con tatuajes tremebundos- bajó el espíritu de un esclavo haitiano del siglo xvi. Allí, en breves horas el haitiano le habló a las personas, dándole consejos y advirtiéndoles sobre posibles percances y se produjo un extraordinario encuentro entre vivos y muertos -de inconfundible carácter popular y democrático-con una huella histórica contundente.

Pero volvamos al poema. Hay referencias a llaves y calabazas, de nuevo objetos cotidianos que de por sí no llaman la atención pero dentro del mundo que exploramos podrían ser referencias a Oggún (las llaves) y a Oshún (la calabaza). De nuevo, la idea no es que el poema está describiendo un ritual santero, todo lo contrario. Lo que logra Morejón es presentar estos objetos normales y calmadamente dejar ver la transformación de los mismos. Lo que a primera vista parece algo humilde y cotidiano pasa a ser algo sagrado, una especie de bisagra que media entre los vivos y los muertos. Cosas parecidas ocurren en los espacios cotidianos de los cubanos. Por ejemplo, en casa de un santero en Cayo Hueso hay un mueble que en parte es gavetero pero con tres niveles de anaqueles que van hacia el techo. Contiene soperas, tiestos con flores, uno que otro caldero de guerreros, unos Elegguás, estatuas de vírgenes, campanitas, agogos, una maraca, velas y otros objetos rituales. Pero también hay fotos de nietos, un muñeco de Santa Claus, un tocadisco, souvenirs de un viaje traído por un ahijado y baterías AAA. En fin, es mueble de sala y altar. Usualmente, cuando hay alguna ceremonia todos los objetos sin función religiosa desaparecen, pero a veces no. La situación misma cambia los objetos en algo

Revista Iberoamericana, Vol. LXXVII, Núm. 235, Abril-Junio 2011, $489-499$
ISSN 0034-9631 (Impreso) 
sagrado. Algo parecido ocurre en el poema de Morejón, donde la palabra empieza a materializar otros significados y contextos, donde lo cotidiano convoca a lo sagrado.

Dicho segmento termina con los "olores fieros, el zumo y el hueso". Sin duda, los olores fieros y los huesos también evocan lo ritual y religioso con igual fuerza. Le siguen dos referencias acuáticas que tienen que ver con los muertos: la primera "En la gota de agua/ está la cara de los muertos", algo que parece aludir directamente a las bóveda espiritista/santera y, la segunda, el trozo de mar donde "se esconde el universo de los muertos”. En fin, estas referencias marítimas parecen aludir a los orichas Yemayá y Olokun, este último quizás porque representa la parte más misteriosa y temible del mar que se asocia con la muerte y el peligro. Aquí hay una dimension histórica difícil de soslayar: la muerte de millones de africanos en su brutal secuestro y viaje mortal por el Atlántico.

Elpróximo verso-con resonancias huidobrianas-retoma las imágenes del principio (lo inerte): "Los muertos cuelgan de las horas". Pero curiosamente "mitigan la sed de un poeta amigo". De nuevo, una imagen misteriosa, porque no sabemos qué tipo de sed, pero debe ser existencial, espiritual. Morejón remata esa interpretación con el final del poema: "Los muertos son/ Los muertos cantan". Al final, entonces, los muertos tienen vida después de su existencia terrenal, son los ciudadanos del cielo (Ará Orún) que todavía conversan y cantan con nosotros.

Morejón coloca "Los muertos" como el tercer poema del libro La Quinta de los Molinos, después de una introducción-prólogo también en forma de poema, en que describe su encuentro con una liebre asustada y perdida. Gabriel Abudu dice que la liebre representa a los cubanos en nuevas circunstancias post-noventa después de la caída del muro de Berlín y las angustiosas incertidumbres del "período especial”, con sus escaseces materiales y desasosiego espiritual. Abudu habla del cubano sin rumbo, resolviendo situaciones como pueda en las calles, llevando un estilo de vida en las fronteras de la ley (Abudu 1024). La autora nos dice que el conejo ha entrado al primer sueño de su infancia. La Quinta de los Molinos, además de ser un lugar conocido de La Habana, va a ser para Morejón una encrucijada de memorias, de meditaciones sobre el pasado. Fue antigua residencia de Máximo Gómez, el ex-Jardín Botánico y hoy en día es un lugar de congregación para la juventud, especialmente aquellos que quieren estar con su pareja un poco escondidos entre la vegetación tupida del lugar. Para Morejón representa toda una red de asociaciones históricas de su pasado, aspecto destacado visualmente en la portada del libro, con un cuadro de Amelia Peláez de la Quinta de los Molinos.

A continuación siguen dos poemas, "La Silla Dorada”, un poema triste y feroz sobre sus abuelas y antepasados, y luego “Otra Canción”, que comienza con una imagen del cementerio chino al atardecer. Es otro himno a La Habana (aunque su descripción del río Almendares no es nada lírica). Termina así: "El sol alumbra y una mujer busca el aliento de su vida/ en la inmensa maravilla del prado./ Mañana sabrá cantar otra canción que se pierda en/ el cielo” (Morejón, Quinta 12).

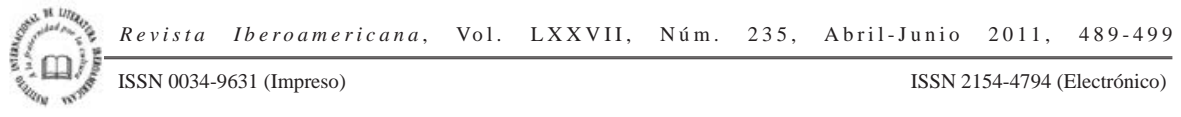


Sin embargo, "Los Muertos" nos remite al último poema de la colección "Premonición" que empieza con una campana que llama a los muertos y termina con su madre huérfana que echa a andar y se va. Se retoman las imágenes del río, la ciudad, los muertos y la canción de una manera sintética.

Hay un poema-bisagra que los vincula. Se titula “A Medio Camino” y, de nuevo, sin ninguna referencia directa contiene una serie de imágenes y alusiones a Ocha. El poema se estructura con tres elementos: el camino, la piedra y el sujeto del poema (¿la misma autora?). Con ellos Morejón va construyendo un poema que es a su vez una descripción de fuerzas naturales (camino, piedra, cielo, jungla, pájaro, perro, etc.), un texto de autorreflexión y una meditación filosófica sobre el tiempo.

Ya el mismo título evoca el epígrafe de Édouard Glissant que abre su novela $L a$ Lézarde (1959) (Ripening 18), tomado de un poema africano que reza así: "Sólo el camino sabe el secreto". Igualmente evoca su conocido poema "Los ojos de Eleggua" con su referencia a las piedras y el camino, y mayor aún en la encrucijada de los cuatro caminos. Comienza el poema con la piedra que ve al borde del camino y que vio casi sin querer. Pero cuando la ve y la nombra ya empieza a ejercer una especie de poder sobre el sujeto-poeta del texto.

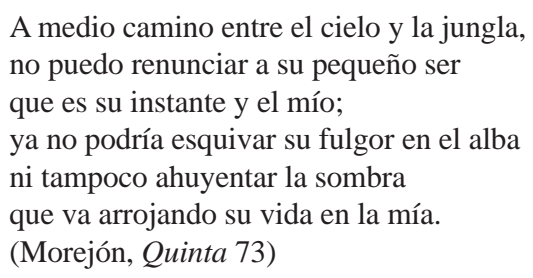

Morejón establece un claro vínculo entre el sujeto y la piedra, incluso equipara sus respectivas dimensiones temporales ("su instante y el mío"). La sombra de la piedra arroja vida en la suya: esta imagen enigmática quizás no lo sea tanto a la luz de Ocha. La piedra es algo muy poderoso, se dice que los primeros orichas se crearon cuando Olofi infundió el aché en algunas piedras. En el caso de Elegguá, es su origen también. Los santeros guardan sus piedras en soperas y se les da de comer en importantes rituales de iniciación, entre otros. Por lo tanto, las piedras sagradas (otanes) contienen aché, el poder de potenciar las cosas, de transformar vidas. También se usa la piedra en el diloggún o el registro, la lectura de los caracoles.

Elegguá-Echu es el mensajero de todos los orichas y forma parte clave de lo que es el sistema adivinatorio yoruba. Interpreta el sistema de Ifá. Henry Louis Gates lo compara a una especie de "crítico literario" en el sentido que lee, interpreta y transmite los signos que genera Ifá sobre nuestro destino (24-26). Es el oricha-portador del aché y nos recuerda que las cosas y los hombres tienen que trabajar armoniosamente o sufrir

Revista Iberoamericana, Vol. LXXVII, Núm. 235, Abril-Junio 2011, $489-499$
ISSN 2154-4794 (Electrónico) 
las consecuencias del desacato. Cada creyente (o persona) tiene su propio Elegguá que rige su propio destino, y en algunos caminos Elegguá es un solitario que vive en el bosque, tal vez recordándonos que muchos hitos en la vida marcan nuestra soledad: el nacimiento, el camino en la vida, la muerte. Elegguá es el tramposo/travieso que accede al pasado, el presente y el futuro, es cifra del tiempo.

Morejón teje su poema sobre el tiempo, valiéndose de la piedra y el camino. A mitad del poema pregunta: “¿Cómo es el mundo y cuándo terminó?” Las dos preguntas chocan, la primera porque la respuesta es muy complicada (o tal vez no tenga respuesta). La segunda porque implica una especie de realidad pos-apocalíptica, un mundo destruido por la guerra o algún tipo de holocausto nuclear, ecológico, tal vez. Pero a continuación se lee "Hay un sonido único que emana de la piedra/ que he colocado en el centro de estos cuatro caminos” (Morejón, Quinta 73). Morejón vuelve a insistir en esta piedra casi musical ("piedra sonora") que también se remonta a la imagen de la piedra con "fulgor" y sus asociaciones con los ojos brillantes de Elegguá.

Los dos animales mencionados por Morejón en el poema son el pájaro y el perro, ambos con ricas asociaciones en el mundo de Ocha. Claro está, se puede hacer una primera lectura menos sobrenatural que se apegue más a las imágenes del cielo (pájaro) y la jungla (perro). Es decir, un animal muy terrestre que conoce por el olfato y otro que vuela, criatura del aire, que frecuentemente se asocia con Obbatalá. Además, las palomas y otras aves se usan para los ebbós (sacrificios) más importantes. Los perros son guardianes de la casa igual que Elegguá-Echu y en algunos de los avatares (o caminos) de Elegguá-Echu hay una relación con el perro que se acerca a Oggún y a Babalu-Ayé, ambos orishas que trabajan de cerca con Elegguá-Eshu. El perro tiene simbólicamente un lugar en la religión afrocubana de Palo Mayombe. En el palo el practicante "trabaja con” y es "trabajado por" un espíritu que reside en un receptáculo que se llama nganga. La nganga que "trabaja" para el palero es llamada también perro-nganga. Pero en el poema de Morejón ella matiza el asunto, ya que pregunta “¿A dónde fueron a parar el pájaro y el perro/ de estos cuatro caminos?” (Quinta 73). De nuevo, falta algo, las imágenes o animales tradicionales no están en la encrucijada anclada por el fulgor de la piedra.

El poema finaliza con la piedra y con el tiempo. Si Elegguá-Echu es intérprete del destino quiere decir que también lo es del tiempo. El diloggún o la lectura de caracoles es precisamente una lectura con los signos del tiempo de cada individuo. Para Morejón, esos signos constituyen, muy borgeanamente, un laberinto: “Una piedra que rueda desde siglos atrás/ y ha preferido el laberinto de las horas,/ el laberinto que teje el tiempo sobre los caminos” (Quinta 73). Los signos espaciales que hemos visto en el texto (piedra, camino, cielo, jungla) devienen signos temporales que a su vez tejen el laberinto del tiempo. La voz poética es una especie de Teseo del tiempo que avanza por los caminos con su piedra-guía sonora. El poema hace (ver cita anterior) varias referencias a laberintos temporales. El sujeto poético va por los caminos espaciales y temporales para poder

\footnotetext{
Revista Iberoamericana, Vol. LXXVII, Núm. 235, Abril-Junio 2011, 489-499
ISSN 0034-9631 (Impreso)
} 
leer los secretos del camino al andarlo, no siempre con éxito (“¿A dónde fueron a parar el pájaro y el perro/ de estos cuatro caminos?”).

En su poema “Expresamente a un árbol” (Looking 152-53) Morejón de nuevo explora el mundo espiritual afrocubano pero sin mención directa de orishas, objetos rituales, etc. Sin embargo, la actitud reverencial que muestra hacia el árbol -de nuevo, sin especificar qué tipo de árbol- hace pensar que le rinde homenaje a la ceiba, árbol de gran valor espiritual para los cubanos. Dice Lydia Cabrera:

La ceiba, como la palma es el árbol característico de la isla y el árbol sagrado por excelencia. Al extremo que cabría preguntarse si es objeto de culto independiente -culto a la ceiba, en el que comulgan por igual, con fervor idéntico, negros y blancossi no supiésemos ya que todos los muertos, los antepasados, los 'santos' africanos de todos las naciones traídas a Cuba y los santos católicos, van a ella y la habitaban permanentemente. (149)

Árbol que tampoco se puede talar o tumbar sin previamente pedirle permiso a los orishas y hacerle ebbós (sacrificios). El huracán no lo puede destruir, ni tampoco lo puede fulminar el rayo.

Morejón comienza su poema así: "En la noche, sigo tus pasos, sigo tu sombra,/ camino a tu lado./ Por eso acudo, como un perro sin prisa, a tu dominio./ Voy contigo” (Looking 152). Todo indica, en el tono de las palabras y en cómo acude el poeta a la sombra del árbol, que se trata de lo espiritual. Cabrera, antes del párrafo citado, tiene un epígrafe que parece enmarcar el poema entero: “Ceiba, tú eres mi madre, dame sombra” (149). Esta imagen protectora de madre, de considerable fuerza, será constante en el poema, como también lo es la sombra de la ceiba, imagen de protección pero con dimensiones espirituales.

En “Expresamente a un árbol” se nota más una vertiente palera. En el Palo Mayombe, que traza sus orígenes a la religión y filosofía kongo-bantú, los hombres y las mujeres se dividen en tres partes: el cuerpo (nitu-bantu), una sombra no-inteligente que también se le dice sombra tonta (nkawama-bantu) y el centro espiritual de la persona, que se llama nfuiri. El nfuiri es un espíritu muy vivo que contiene a su vez tres componentes: la sombra inteligente (nkawama-ntu), conocido como el cuerpo astral, una inteligencia (ntu) y el don de la palabra y la personalidad (ndinga) (Castellanos y Castellanos 13031). Si la ceiba es un santo (llamada Iroko por los santeros) podemos interpretar este poema y el árbol que evoca Morejón como fuerza natural-cósmica que contiene estas sombras (inteligentes y no), que protegen a la poeta.

La autora recuerda que empezó a admirar la belleza del árbol cuando conoció el amor, pero a continuación se lee "Sé que debo transcurrir" (Looking 152). Curiosa expresión que muestra a la vez la frágilidad de su existencia frente a lo que parece la eternidad del árbol y su propia confluencia con el tiempo. Si bien retoma el tema del

Revista Iberoamericana, Vol. LXXVII, Núm. 235, Abril-Junio 2011, $489-499$
ISSN 0034-9631 (Impreso) 
tiempo que caracterizó “A Medio Camino”, en su poema al árbol Morejón parece entrar en otro tiempo (sagrado), que implica tanto el sacrificio ("cargar tus zumos”, "devolver los días incógnitos de ayer”), un descanso anímico ("reposar bajo tus flores”) y una afiliación completa a su poder espiritual ("siempre vendré a que me veas rondar, junto a tu sombra”).

Como se dijo anteriormente, Morejón juega con la imagen de la sombra física que da el árbol haciendo que a la vez resalte todo el aspecto espiritual del vocablo. El cuerpo astral (o la sombra inteligente) mantiene un vínculo entre la dimensión espiritual y material del ser humano. Morejón sutilmente sugiere un “triálogo” entre la sombra de Iroko, como también con los nfuiri-toto o espíritus de muertos que allí habitan y su propia vida, que contiene sus propias sombras (inteligente y tonta), palabras y personalidad. El poema teje estas distintas sombras que conversan, caminan, dan reposo y se animan mutuamente.

Tal vez el poema de Morejón donde mejor sintetiza estas preocupaciones e imágenes se titula “Tambor”. De nuevo, como en el poema del árbol, no hay indicio de qué tipo de tambor, cosa que podría frustrar al lector ya que en un país como Cuba hay un sinnúmero de tambores que se pueden evocar (congas, batás, abakuá, yuka, bongó, tumba francesa, bongoes). Ni siquiera menciona el tambor en el poema fuera del título; tampoco intenta recrear miméticamente un ritmo en particular. Sí, se vale de la repetición (“mi cuerpo”); más conveniente sería ver el poema como una irradiación desde su cuerpo que va dialogando con el tambor.

La sensualidad y corporalidad del poema no están en contradicción con su intensa espiritualidad, algo que también distingue a las religiones afrocubanas, o como se dice hoy día, religiones cubanas de descendencia africana. En la Regla de Ocha casi todas las ceremonias tienen un vínculo íntimo con el cuerpo: ya sea la lectura de caracoles que entabla una relación corporal muy especial entre el oriaté y el/la que procura la lectura, o la rogación de cabeza. También para la posesión por espíritus u orichas, la rapadura de la cabeza en los ritos de iniciación: el mundo material y espiritual se comunican y se transforman. Esto sin mencionar una de las ceremonias más hermosas de la religión que es el tambor.

En el tambor se le prepara comida en ofrenda al oricha que hay que conmemorar: es una fiesta que convoca y honra la presencia de un oricha particular. Es durante esta ceremonia que la posesión de un creyente por un orisha se da con mayor frecuencia. Los tambores batás empleados en esta ceremonia son consagrados y tienen su propio aché. Los santeros rinden culto al tambor besándolos y poniendo la frente sobre ellos mientras se tocan. La vibración del tambor y el aché que transmite-con dulzura y fuerza a la vez- van directo a la cabeza, como un relámpago de aché.

No menciono el tambor para ver si se encuentran análogos idénticos en el poema de Morejón sino para evocar su cruce de energías y poderes. Cuando Morejón dice que su cuerpo convoca la llama y los humos, ya nos indica la incandescencia y el poder

\footnotetext{
Revista Iberoamericana, Vol. LXXVII, Núm. 235, Abril-Junio 2011, 489-499
ISSN 0034-9631 (Impreso)
} 
del mundo que va creando. Es difícil no pensar en Yemayá cuando escribe "Mi cuerpo en el coral.../ Fuego sobre mis aguas/ Aguas irreversibles/ en los azules de la tierra” (Looking 156).

Esta referencia a la oricha de los mares y la maternidad va seguida de "Mi cuerpo como las codornices/ Mi cuerpo en una pluma./ Mi cuerpo al sacrificio” (156). Aquí Morejón reúne dos elementos fundamentales de Ocha, el aché (la pluma) y el ebbó (sacrificio). El aché es tal vez el concepto fundamental de la religión yoruba: es la fuerza cósmica de la vida y el universo, lo que hace funcionar y transformar todo lo que nos rodea. Todos necesitamos aché, no importa cuán piadosos (o no) seamos, pero sólo los orichas son portadores de ese aché. Para obtenerlo hay que hacer sacrificios, el aché no viene gratis. El aché es lo que nos da iwa pelé (buen carácter, ecuanimidad), un fulgor del espíritu, esos ojos interiores o espirituales que nos alumbra. Morejón alude a esto en los próximos versos: “Mi cuerpo en la penumbra/ Mi cuerpo en claridad” (156).

Vuelvo a insistir en que el poema no es una descripción de una ceremonia: esto no es antropología en verso sino una constelación de imágenes que va recogiendo una memoria y unas tradiciones orales que han sido vividas por la autora. Son destellos en los versos que recuerdan, transforman y hasta cambian estas tradiciones con el poder de sus imágenes.

$\mathrm{Al}$ hacer lectura de la relación en estos poemas con temas soterrados pero siempre expresados en la poesía, quiero subrayar la movilidad de ciertas imágenes y también las imágenes de movilidad que impregnan la poesía de Morejón. En otro ensayo sobre Morejón analicé la obra de Bachelard y su relevancia para su poética, destacando la importancia del aire y el agua como portadores de movimiento que estimulan la imaginación:

We always think of the imagination as the faculty that forms images. On the contrary, it deforms what we perceive; it is, above all, the faculty that frees us from immediate images and changes them. If there is no change, or unexpected fusion of images, there is no imagination; there is no imaginative act. If the image that is present does not make us think of one that is absent, if an image does not determine an abundance-an explosion-of unusual images, then there is no imagination There is only perception, the memory of a perception, a familiar memory, an habitual way of viewing form and color. (Bachelard 1)

Un poco después Bachelard subraya la diferencia entre percibir e imaginar de esta forma:

Perceiving and imagining are as antithetical as presence and absence. To imagine is to absent oneself, to launch out toward a new life [...] A true poet is not satisfied with escapist imagination. He [sic] wants the imagination to be a journey. (3)

Revista Iberoamericana, Vol. LXXVII, Núm. 235, Abril-Junio 2011, 489-499 
Usé estas citas que bien sirven para discutir La Quinta de los Molinos y otros textos, para enmarcar mi análisis de su poema "Elogio de Nieves Fresneda”. En un poema como "Los muertos" Morejón no se limita a recuperar ciertas imágenes o memorias sino que las deforma y las transforma en algo nuevo hasta que los muertos cantan. Del mismo modo, en el poema final su madre va caminando hacia una nueva vida, aunque sea vida huérfana. En “A medio camino” es el camino propio y el laberinto del tiempo que evocan la movilidad; en "Expresamente a un árbol”, el transcurrrir y volver del sujeto y su rodeo a la sombra del árbol. Se podría argumentar que lo mismo pasa en Regla de Ocha: las imágenes, la percepción, también cambian o se deforman, mientras uno va pasando por los distintos niveles de iniciación. De esa manera podemos ver que la imaginación poética de Morejón se nutre de la imaginación poética-filosófica yoruba, que de igual manera deforma y transforma lo cotidiano en sagrado. El movimiento de ausencia-presencia que articula Bachelard como central en la imaginación es medular en la poética de Nancy Morejón. La Habana con sus ausencias y presencias, sus vivos y sus muertos, es lo que transforma Nancy Morejón con su aché de la palabra, sangre cósmica que alimenta, sonido y sentido que infunden la expresión de su cubanía con una profunda espiritualidad africana.

\section{BiBLIOGRAFÍA}

Abudu, Gabriel. "Havana as Poetic and Personal Space in the Works of Nancy Morejón.” Callalloo 28 [Número especial sobre Nancy Morejón] (otoño 2005): 1012-26.

Bachelard, Gaston. Air and Dreams: An Essay on the Imagination of Movement. Dallas: Dallas Institute of Humanities, 1988.

Cabrera, Lydia. El monte. Miami: Universal, 1992.

Castellanos, Jorge e Isabel Castellanos. Cultura Afrocubana 3. Las religiones y las lenguas. Miami: Universal, 1992.

Gates, Henry Louis. The Signifying Monkey. New York: Oxford UP, 1989.

Glissant, Édouard. The Ripening. [La Lézarde]. Michael Dash, trad. Londres: Heineman, 1985.

González, Patricia. “Yoruba Vestiges in Nancy Morejon’s Poetry.” Callalloo 28 [Número especial sobre Nancy Morejón] (otoño 2005): 952-66.

Morejón, Nancy. Looking Within/Mirar Adentro, Selected Poems 1954-2000. Juanamaría Cordones-Cook, ed. e intro. Detroit: Wayne State UP, 2003. Nación y mestizaje en Nicolás Guillén. La Habana: UNEAC, 1982. La Quinta de los Molinos. La Habana: Letras Cubanas, 2000. Where the Island Sleeps Like A Wing. Kathleen Weaver, trad. San Francisco: Black Scholar, 1985.

\footnotetext{
Revista Iberoamericana, Vol. LXXVII, Núm. 235, Abril-Junio 2011, $489-499$
ISSN 0034-9631 (Impreso)
} 
West, Alan. "Nancy Morejón, The Stone and Its Images.” Tropics of History. Westport: Greenwood, 1997. 13-34.

West-Durán, Alan. "Nancy Morejón: Transculturation, Translation, and the Poetics of the Caribbean.” Callalloo 28 [Número especial sobre Nancy Morejón] (otoño 2005): 967-76. $\begin{array}{llllll}\text { Revista Iberoamericana, Vol. LXXVII, Núm. 235, } & \text { Abril-Junio 2011, } & \text { 489-499 } \\ \text { ISSN 0034-9631 (Impreso) } & \text { ISSN 2154-4794 (Electrónico) }\end{array}$ 
